University of Wollongong

Research Online

Australian Institute for Innovative Materials -

Papers

Australian Institute for Innovative Materials

$1-1-2013$

Intrinsically stretchable supercapacitors composed of polypyrrole electrodes and highly stretchable gel electrolyte

Chen Zhao

University of Wollongong, cz995@uowmail.edu.au

Caiyun Wang

University of Wollongong, caiyun@uow.edu.au

Zhilian Yue

University of Wollongong, zyue@uow.edu.au

Kewei Shu

University of Wollongong, ks323@uowmail.edu.au

Gordon G. Wallace

University of Wollongong, gwallace@uow.edu.au

Follow this and additional works at: https://ro.uow.edu.au/aiimpapers

Part of the Engineering Commons, and the Physical Sciences and Mathematics Commons

Research Online is the open access institutional repository for the University of Wollongong. For further information contact the UOW Library: research-pubs@uow.edu.au 


\title{
Intrinsically stretchable supercapacitors composed of polypyrrole electrodes and highly stretchable gel electrolyte
}

\author{
Abstract \\ There has been an emerging interest in stretchable power sources compatible with flexible/wearable \\ electronics. Such power sources must be able to withstand large mechanical strains and still maintain \\ function. Here we report a highly stretchable H3PO4-poly(vinyl alcohol) (PVA) polymer electrolyte \\ obtained by optimizing the polymer molecular weight and its weight ratio to H3PO4 in terms of \\ conductivity and mechanical properties. The electrolyte demonstrates a high conductivity of $3.4 \times 10-3 \mathrm{~S}$ \\ $\mathrm{cm}-1$, and a high fracture strain at $410 \%$ elongation. It is mechanically robust with a tensile strength of 2 \\ $\mathrm{MPa}$ and a Young's modulus of $1 \mathrm{MPa}$, and displays a small plastic deformation (5\%) after 1000 \\ stretching cycles at $100 \%$ strain. A stretchable supercapacitor device has been developed based on \\ buckled polypyrrole electrodes and the polymer electrolyte. The device shows only a small capacitance \\ loss of $5.6 \%$ at $30 \%$ strain, and can retain $81 \%$ of the initial capacitance after 1000 cycles of such \\ stretching.

\section{Keywords} \\ polypyrrole, composed, supercapacitors, stretchable, intrinsically, gel, highly, electrolyte, electrodes

\section{Disciplines} \\ Engineering | Physical Sciences and Mathematics

\section{Publication Details} \\ Zhao, C., Wang, C., Yue, Z., Shu, K. \& Wallace, G. G. (2013). Intrinsically stretchable supercapacitors \\ composed of polypyrrole electrodes and highly stretchable gel electrolyte. ACS Applied Materials and \\ Interfaces, 5 (18), 9008-9014.
}




\title{
Intrinsically Stretchable Supercapacitors Composed of Polypyrrole Electrodes and Highly Stretchable
}

\author{
Gel Electrolyte
}

Chen Zhao, Caiyun Wang*, Zhilian Yue, Kewei Shu, Gordon G. Wallace*

Intelligent Polymer Research Institute, ARC Centre of Excellence for Electromaterials Science, AIIM Facility, Innovation Campus, University of Wollongong, Wollongong, NSW, 2522,

Australia

ABSTRACT: There has been an emerging interest in stretchable power sources compatible with flexible/wearable electronics. Such power sources must be able to withstand large mechanical strains and still maintain function. Here we report a highly stretchable $\mathrm{H}_{3} \mathrm{PO}_{4}$-poly(vinyl alcohol) (PVA) polymer electrolyte obtained by optimizing the polymer molecular weight and its weight ratio to $\mathrm{H}_{3} \mathrm{PO}_{4}$ in terms of conductivity and mechanical properties. The electrolyte demonstrates a high conductivity of $3.4 \times 10^{-3} \mathrm{~S} \mathrm{~cm}^{-1}$, and a high fracture strain at $410 \%$ elongation. It is mechanically robust with a tensile strength of $2 \mathrm{MPa}$ and a Young's modulus of $1 \mathrm{MPa}$, and displays a small plastic deformation (5\%) after 1000 stretching cycles at $100 \%$ strain. A stretchable supercapacitor device has been developed based on buckled polypyrrole electrodes and the polymer electrolyte. The device shows only a small capacitance loss of $5.6 \%$ at $30 \%$ strain, and can retain $81 \%$ of the initial capacitance after 1000 cycles of such stretching. 
KEYWORDS: stretchable supercapacitor, electropolymerization, buckled structure, polypyrrole, stretchable polymer electrolyte

\section{INTRODUCTION}

Stretchable electronics, also known as elastic electronics or elastic circuits, is a technology for building electronic circuits by depositing stretchable electronic devices and circuits onto or embedding them completely into stretchable substrates. ${ }^{1}$ Research on stretchable electronics is motivated by the need for electronic systems that can sustain large mechanical strain. They have found broad applications in stretchable devices, such as p-n diodes, ${ }^{2}$ polymer light-emitting diodes,${ }^{3,4}$ transistors, ${ }^{5-7}$ electronic eyes, ${ }^{8}$ active matrix displays,,${ }^{9,10}$ and strain sensors. ${ }^{11,12}$

To achieve an integrated stretchable electronic system, a stretchable power source is required. Recently, there has been an emerging interest in stretchable energy storage including supercapacitors ${ }^{13-16}$ and batteries. ${ }^{17-19}$ Combining such stretchable energy storage devices with the energy harvesting systems to capture energy from human body heat or movement is a promising solution for future wearable electronics. ${ }^{20}$ Supercapacitors have attracted tremendous attention due to their high power density and long cycle life. ${ }^{21}$ Single-walled carbon nanotube (SWNT) macrofilms on pre-strained poly(dimethylsiloxane) (PDMS), ${ }^{13,14}$ SWNT coated textile ${ }^{15}$ and polypyrrole coated fabric ${ }^{16}$ were developed as stretchable supercapacitor electrodes. Buckled SWNT macrofilms on PDMS showed a specific capacitance of $54 \mathrm{~F} \mathrm{~g}^{-1}$ without strain and $52 \mathrm{~F}$ $\mathrm{g}^{-1}$ with $30 \%$ strain at a current density of $1 \mathrm{~A} \mathrm{~g}^{-1}$, the specific capacitance did not change up to 1000 charge-discharge cycles. A stretchable supercapacitor fabricated by using SWNT coated textile exhibited a specific capacitance of $62 \mathrm{~F} \mathrm{~g}^{-1}$ at a current density of $1 \mathrm{~mA} \mathrm{~cm}{ }^{-2}$, and no obvious capacitance loss was observed after being subjected to 100 stretching cycles with $120 \%$ elongation. The specific capacitance on polypyrrole coated fabric without strain was $108.5 \mathrm{~F} \mathrm{~g}^{-1}$ 
and this increased to $125.1 \mathrm{~F} \mathrm{~g}^{-1}$ with $60 \%$ elongation. However, the leakage of liquid electrolyte is a risk when those fabricated supercapacitors are integrated into electronic system.

An intrinsically stretchable supercapacitor requires each device component including electrodes, separator and electrolyte to be stretchable. Compared to liquid electrolyte, polymer electrolytes have several advantages over liquid electrolytes including the ability to minimize percent leakage of electrolytes and ensure non-flammable reaction products at the surface of electrodes. $^{22-24}$ They have been widely used in energy conversion and storage devices. ${ }^{25-28}$ Currently, there are only a few stretchable solid electrolytes reported such as graft copolymer poly[(oxyethylene) ${ }_{9}$ methacrylate]-g-poly(dimethylsiloxane) doped with $\mathrm{LiCF}_{3} \mathrm{SO}_{3}{ }^{29}$ poly(methyl methacrylate) networks solvated by the ionic liquid 1-ethy-3-methylimidazolium bis(trifluoromethanesulfonyl) imide (EMI.TFSI). ${ }^{30}$ The fabrication of these electrolytes involves complicated chemical reaction/polymerization, and their conductivities are low $\left(10^{-5}-10^{-4} \mathrm{~S} \mathrm{~cm}^{-}\right.$ ${ }^{1}$ ). $\mathrm{H}_{3} \mathrm{PO}_{4}$-PVA or $\mathrm{H}_{2} \mathrm{SO}_{4}$-PVA is a commonly used gel electrolyte in flexible energy devices. ${ }^{31,32}$ Very recently, a stretchable $\mathrm{H}_{2} \mathrm{SO}_{4}$-PVA gel electrolyte has been used to prepare stretchable integrated supercapacitor which can sustain $120 \%$ strain. $^{33}$ It is fabricated by a solvent casting method. However, there is no report on the mechanical properties and stretchability of this electrolyte available. The lack of such knowledge will limit its wide application as a stretchable electrolyte.

Here, we report a highly stretchable electrolyte with high conductivity and mechanical properties. PVA with a molecular weight of $124,000-186,000 \mathrm{~g} \mathrm{~mol}^{-1}$ was chosen and the PVA $/ \mathrm{H}_{3} \mathrm{PO}_{4}$ weight ratio was optimized. The optimized electrolyte was then coupled with buckled, stretchable polypyrrole electrodes to form an intrinsically stretchable supercapacitor device. The polypyrrole electrode was prepared using a facile electropolymerization method as 
described in our previous report. ${ }^{34}$ Such supercapacitor can sustain 1000 stretching cycles with $30 \%$ strain applied.

\section{EXPERIMENTAL SECTION}

Materials. Pyrrole was sourced from Merck, $p$-toluenesulfonic acid and PVA were obtained from Sigma-Aldrich. Orthophosphoric acid (85\%) and acetonitrile were purchased from Ajax Finechemicals. Pyrrole was freshly distilled, while all the other chemicals were used as-supplied.

Preparationof stretchable polymer electrolyte. Stretchable polymer electrolyte was prepared by solvent casting method. PVA ( $1 \mathrm{~g})$ was dissolved in Milli-Q water $(10 \mathrm{~mL})$ at $90{ }^{\circ} \mathrm{C}$ under vigorous stirring until the solution became clear, then an appropriate amount of $\mathrm{H}_{3} \mathrm{PO}_{4}$ was added into the hot solution and stirred at room temperature overnight. The viscous solutions were cast onto Teflon molds and dried in a vacuum oven at $40{ }^{\circ} \mathrm{C}$ for $24 \mathrm{~h}$. The dried films were peeled off from the molds and cut into $30 \mathrm{~mm} \times 10 \mathrm{~mm}$ specimens for further tests.

Preparation of stretchable polypyrrole electrodes. Buckled, stretchable polypyrrole electrodes on Au-coated elastomer poly (styrene-block-isobutylene-block-styrene) (SIBS) substrate were prepared using a procedure established previously. ${ }^{34}$ Briefly, SIBS substrate was prepared by solvent casting from a solution in toluene. A thin Au film of about $30 \mathrm{~nm}$ thickness was sputter coated on pre-strained SIBS substrate using an Edwards Auto 306 Sputter Coater, followed by release of the strain to obtain buckled Au microfilms. Polypyrrole with dopant of ptoluenesulfonic acid was galvanstatically electropolymerized on the re-elongated conductive substrate from the solution containing $0.10 \mathrm{M}$ pyrrole and $0.10 \mathrm{M}$ p-toluenesulfonic acid in acetonitrile at $0{ }^{\circ} \mathrm{C}$ to a charge density of $0.25 \mathrm{C} \mathrm{cm}^{-2}$. The applied current density was $0.25 \mathrm{~mA}$ $\mathrm{cm}^{-2}$. 
Fabrication of stretchable supercapacitor. The stretchable supercapacitor was fabricated by assembling the stretchable polypyrrole electrodes and stretchable polymer electrolyte in a sandwich configuration. Copper wires were attached on the uncovered gold film of the stretchable polypyrrole electrodes by silver paste for electrical contact. The $\mathrm{H}_{3} \mathrm{PO}_{4}-\mathrm{PVA}$ solution was heated to $80{ }^{\circ} \mathrm{C}$ then the buckled polypyrrole electrodes were immersed in this solution for $10 \mathrm{~min}$, followed by leaving the electrodes in fume hood for $4 \mathrm{~h}$ to remove most of the water contained. Such two polypyrrole electrodes with polymer electrolyte were pressed together faceto-face to form a sandwich structure. The whole device was dried at room temperature overnight.

Characterization. The morphology of the buckled polypyrrole electrode was characterized by FE-SEM (JEOL JSM-7500FA). The mechanical properties of the stretchable polymer electrolyte were conducted using Shimadzu EZ mechanical tester with 50N load cell at a stretching speed of $25 \% \mathrm{~min}^{-1}$, and the gauge length was $20 \mathrm{~mm}$. The samples were stretched and released at a speed of $50 \% \mathrm{~s}^{-1}$ for 1000 cycles for stretchability test. The ionic conductivity was determined using AC impedance using a Gamry EIS 3000 ${ }^{\mathrm{TM}}$ system in the frequency range of $100 \mathrm{kHz}$ to $1 \mathrm{~Hz}$ at $30{ }^{\circ} \mathrm{C}$. For this measurement, the sample was sandwiched between two stainless steel plates with a testing area of $1.4 \mathrm{~cm}^{2}$. The ionic conductivity is estimated according to the following equation:

$$
\sigma=\frac{\mathrm{T}}{\mathrm{RA}}
$$

where $\mathrm{T}$ is the thickness of the film $(\mathrm{cm}), \mathrm{R}$ is the bulk resistance $(\Omega)$ obtained from the first intercept on the $\mathrm{x}$-axis of the impedance data in the complex plane, and $\mathrm{A}$ is the contact area $\left(\mathrm{cm}^{2}\right)$.The effects of temperature and strain on the electrolyte conductivity were investigated between $30{ }^{\circ} \mathrm{C}$ and $70{ }^{\circ} \mathrm{C}, 0 \%$ and $100 \%$ strain, respectively. 
The cross-section of the stretchable supercapacitor was characterized using an optical microscope (Leica DM6000). Cyclic voltammetry (CV) of the stretchable supercapacitor was conducted from 0V to $0.8 \mathrm{~V}$ using $\mathrm{CHI}$ 650D (CHI instruments). Electrochemical impedance spectra were measured using Gamry EIS $3000^{\mathrm{TM}}$ system in the frequency range of $100 \mathrm{kHz}$ to $0.01 \mathrm{~Hz}$ with an AC perturbation of $10 \mathrm{mV}$ at open circuit potential. Galvanostatic chargedischarge tests of the stretchable supercapacitor were performed using a battery test system (Neware electronic Co.) between $0 \mathrm{~V}$ and $0.8 \mathrm{~V}$. Specific capacitance $\left(\mathrm{C}_{\mathrm{sp}}\right)$ of the supercapacitor was calculated from the constant current charge-discharge curves using the following equation: ${ }^{35}$

$$
C_{s p}=\frac{I}{m \cdot \frac{d V}{d t}}
$$

Where $I$ is the discharge current, $\mathrm{dV} / \mathrm{dt}$ is the slope of the discharge curve and $\mathrm{m}$ is the total mass of the polypyrrole films on both electrodes.

\section{RESULTS AND DISCUSSION}

Properties of the stretchable polymer electrolyte. PVA with varying molecular weight of $30,000-50,000,85,000-14,6000$ and $124,000-186,000 \mathrm{~g} \mathrm{~mol}^{-1}$ were used to prepare the electrolytes investigate here. It was found that stretchable $\mathrm{H}_{3} \mathrm{PO}_{4}$-PVA film could be obtained only with high molecular weight PVA $\left(124,000-186,000 \mathrm{~g} \mathrm{~mol}^{-1}\right)$ at the weight ratio of 1:1. No films could be formed using low molecular weight PVA (30,000-50,000 $\left.\mathrm{g} \mathrm{mol}^{-1}\right)$. The film obtained from the PVA of medium molecular weight $\left(85,000-146,000 \mathrm{~g} \mathrm{~mol}^{-1}\right)$ was very sticky and didn't return to the original dimensions after being stretched and released. $\mathrm{H}_{3} \mathrm{PO}_{4}$ is known act as a plasticizer in the PVA matrix. When $\mathrm{H}_{3} \mathrm{PO}_{4}$ was added, the free volume of PVA increased, the segment in low molecular weight PVA matrix had higher mobility than that in PVA with higher molecular weight, resulting in relatively lower mechanical strength. ${ }^{36}$ At this weight ratio, the polymer chains in low molecular weight PVA didn't come into contact with 
each other, so no stable film was formed. When the molecular weight increased, the longer polymer chains begun to overlap and entangle with each other, leading to stretchable film. ${ }^{37}$

The effect of the weight ratio $\mathrm{H}_{3} \mathrm{PO}_{4} / \mathrm{PVA}$ was also investigated over the range 0.5:1, 1:1, 1.5:1, 2:1 and 3:1. Stretchable films were formed only from the solution with $\mathrm{H}_{3} \mathrm{PO}_{4} / \mathrm{PVA}$ ratio of 1:1 and 1.5:1. In the dry films, the weight ratio of pure $\mathrm{H}_{3} \mathrm{PO}_{4}$ to PVA were $0.85: 1$ and $1.28: 1$ (the concentration of $\mathrm{H}_{3} \mathrm{PO}_{4}$ was $85 \%$ ), the water content was about $2 \%$. The mechanical properties of these two stretchable electrolytes are shown in Figure 1, together with that of pure PVA for comparison. With the increase of $\mathrm{H}_{3} \mathrm{PO}_{4}$ content, the tensile stress and Young's modulus decreased, while the elongation to break was enhanced, indicating that the film became softer with increasing $\mathrm{H}_{3} \mathrm{PO}_{4}$ content. Pure PVA is partially crystalline and consists of crystalline layers of folded chains. The interactions between $\mathrm{H}_{3} \mathrm{PO}_{4}$ and the polymer chain network lead to an increasing portion of amorphous region. ${ }^{38}$ According to the free volume theory, ${ }^{36}$ the free volume of PVA increased with the increasing content of $\mathrm{H}_{3} \mathrm{PO}_{4}$, which enhanced the PVA chain mobility leading to the improved elasticity until the $\mathrm{H}_{3} \mathrm{PO}_{4} / \mathrm{PVA}$ ratio of 1.5 . When the content of $\mathrm{H}_{3} \mathrm{PO}_{4}$ continued to rise, the entangled polymer chains started to lose entanglement with each other, resulting in unstretchable film, and finally no stable film was formed.

The ionic conductivity was found to increase from $9.6 \times 10^{-4} \mathrm{~S} \mathrm{~cm}^{-1}$ to $3.44 \times 10^{-3} \mathrm{~S} \mathrm{~cm}^{-1}$ as the weight ratio of $\mathrm{H}_{3} \mathrm{PO}_{4} / \mathrm{PVA}$ rose from 1.0:1 to 1.5:1, this is attributed to the increased number of charge carriers, $\mathrm{H}^{+}$ions from $\mathrm{H}_{3} \mathrm{PO}_{4}{ }^{39}$ This value is comparable to the conductivity of $0.05 \mathrm{M}$ $\mathrm{H}_{3} \mathrm{PO}_{4}\left(5.5 \times 10^{-3} \mathrm{~S} \mathrm{~cm}^{-1}\right)$, and $1 \mathrm{M} \mathrm{LiClO}_{4}$ in propylene carbonate $\left(\sim 10^{-3} \mathrm{~S} \mathrm{~cm}^{-1}\right){ }^{40} \mathrm{The}_{3} \mathrm{PO}_{4^{-}}$ PVA (1.5:1) polymer electrolyte was selected for further tests due to its higher elasticity and conductivity. The conductivity increased as the temperature went up in the range of $30{ }^{\circ} \mathrm{C}$ to 70 
${ }^{\circ} \mathrm{C}$ (Figure 2a-b), indicating an Arrhenius type thermally activated process. This process can be expressed as:

$$
\sigma=\sigma_{0} \exp \left(-\frac{E_{a}}{\mathrm{kT}}\right)
$$

where $\sigma_{0}$ is the pre-exponential factor and $E_{a}$ is the activation energy required for the process. The estimated values of the pre-exponential factor $\sigma_{0}$ and the activation energy $E_{a}$ from the curve are 10.57 and $0.20 \mathrm{eV}$. Similar results were reported by Kufian and coworkers. ${ }^{39}$ The increase in conductivity with temperature can be explained by a hopping mechanism between coordinating sites, local structure relaxation and segmental motions of the polymer electrolyte complexes. As temperature increases, the polymer chain moves faster in which bond rotation produces segmental motion. Accordingly, the ion movements become faster, leading to higher conductivity. ${ }^{41}$ The conductivity of the stretchable electrolyte under various strains up to $100 \%$ remained fairly constant at approximately $3.4 \times 10^{-3} \mathrm{~S} \mathrm{~cm}^{-1}$ (Figure 2c-d).

The electrolyte was then subjected to 1000 strain cycles with 100\% elongation applied. The accumulation of plastic deformation (defined as the length increase at the relaxation state), and the variation in conductivity of the electrolyte film were investigated. No plastic deformation was observed for the first 100 cycles, and the deformation was only 5\% after 1000 cycles (Figure 3), indicating that this electrolyte is highly stretchable. The conductivity remained constant after such 1000 cycles of elongation-relaxation, which was still $3.1 \times 10^{-3} \mathrm{~S} \mathrm{~cm}^{-1}$. These results clearly demonstrate that this stretchable electrolyte is mechanically robust.

Electrochemical properties of the stretchable supercapacitor. The polypyrrole electrode exhibited a buckled structure along the elongation direction with 1 buckle per $\mu \mathrm{m}$, and polypyrrole film displayed a cauliflower morphology composed of large nodules (Figure 4a-c). The highly stretchable electrolyte layer formed between two electrodes serves as separator and 
electrolyte, which enables the whole device intrinsically stretchable. The thickness of the electrolyte layer was about $100 \mu \mathrm{m}$ (Figure 4d). The schematic configuration of this supercapacitor is also presented for easy understanding (Figure 4e).

The strain applied to test our stretchable supercapacitor was 30\%, same as that used for polypyrrole electrodes in our previous report. ${ }^{34}$ It should be also pointed out that the application of this highly stretchable electrolyte is currently limited by our stretchable polypyrrole electrodes. The supercapacitor exhibited nearly rectangular CV responses at the relaxation state (i.e. no strain applied) at scan rates up to $50 \mathrm{mV} \mathrm{s}^{-1}$ (Figure 5a), which indicated that the chargedischarge processes were highly reversible and kinetically facile. When the scan rate reached 100 $\mathrm{mV} \mathrm{s}^{-1}$, the rectangular $\mathrm{CV}$ shape became distorted. This may be attributed to the inclusion/ejection and diffusion of counter ions being slow compared to the transfer of electrons in the polypyrrole matrix at high scan rates. ${ }^{16}$ With $30 \%$ strain applied, the supercapacitor maintained similar CV responses (Figure 5b), suggesting that this supercapacitor was stretchable. The specific capacitances of the supercapacitor at $0 \%$ and 30\% strain at different scan rates are presented in Figure 5c for comparison. The specific capacitance decreased with the increase of scan rate, this is because at lower scan rates, there is enough time for ions to complete the redox process, resulting in higher capacitance. The supercapacitor at 30\% stain delivered lower capacitance than that without strain, which might be due to the decreased electrical conductivity of the buckled polypyrrole electrodes induced by the applied strain.

Impedance spectroscopy was performed to gain an insight into the electrochemical interface properties of the stretchable supercapacitor. The Nyquist plots of the stretchable supercapacitor with $0 \%$ and $30 \%$ strain are shown in Figure $5 \mathrm{~d}$. The stretchable supercapacitor with $0 \%$ and $30 \%$ strain all showed a line close to $90^{\circ}$ at low frequency, indicating a good capacitive 
behavior. ${ }^{42}$ At high frequency, the intercept point on the real axis represents the resistance of the electrolyte and the internal resistance of the electrodes, which can be called bulk resistance, and the diameter of compressed semicircle is attributed to charge transfer resistance. ${ }^{43}$ Both the bulk resistance and charge transfer resistance increased with the applied strain, which agrees with the results from $\mathrm{CV}$. The equivalent series resistance (ESR) of the stretchable supercapacitor at $0 \%$ and $30 \%$ strain was $9.9 \Omega$ and $16.5 \Omega$, respectively. Accordingly, the maximum powers could be delivered were $16.2 \mathrm{~mW}$ and $9.7 \mathrm{~mW}$, respectively. Wearable system usually contains devices with low-power requirement. For example, a wireless sensors network showed a sensitivity of $60 \mathrm{dBm}$ with a power consumption of $6.3 \mathrm{~mW}$ from a $1.8 \mathrm{~V}$ supply, ${ }^{44}$ our device can be connected in series to meet this requirement.

The charge-discharge curves of the supercapacitor with $0 \%$ and $30 \%$ strain at a current density of $0.5 \mathrm{~A} \mathrm{~g}^{-1}$ are presented in Figure 6a. The specific capacitance of the supercapacitor without strain was $23.2 \mathrm{~F} \mathrm{~g}^{-1}$, and $94.4 \%$ of the capacitance was retained $\left(21.9 \mathrm{~F} \mathrm{~g}^{-1}\right)$ at $30 \%$ elongation. In the case of a single electrode, its specific capacitance without strain was $92.8 \mathrm{~F} \mathrm{~g}^{-1}$. This value was slightly higher than that $84 \mathrm{~F} \mathrm{~g}^{-1}$ offered from polypyrrole electrodeposited on ITO glass using a $\mathrm{H}_{3} \mathrm{PO}_{4} / \mathrm{PVA}$ polymer electrolyte reported by Hashmi et al. ${ }^{45}$ This stretchable supercapacitor was also investigated after being subjected to 30\% strain for up to 1000 stretching cycles at a stretching speed of $2 \% \mathrm{~s}^{-1}$. A notable IR drop was observed after 1000 stretching cycles (Figure 6b), which can be ascribed to the resistance increase induced by the cracks formed on the buckled polypyrrole film after the continuous stretching. This stretchable supercapacitor delivered a specific capacitance of $20.6 \mathrm{~F} \mathrm{~g}^{-1}, 20.0 \mathrm{~F} \mathrm{~g}^{-1}$ and $18.8 \mathrm{~F} \mathrm{~g}^{-1}$ after 100, 500 and 1000 stretching cycles with 30\% strain applied, respectively (Figure 6c). It still retained about 81.0\% 
of the capacitance after 1000 stretching cycles, suggesting the high stretchability of our supercapacitor device.

The cycling stability of the stretchable supercapacitor was assessed at a current density of 0.5 $\mathrm{A} \mathrm{g}^{-1}$ for 2000 cycles with $0 \%$ and 30\% strain applied (Figure 6d). The stretchable supercapacitor retained $83.6 \%$ of its initial capacitance with $0 \%$ strain, and $74.4 \%$ with $30 \%$ strain. The capacitance loss observed can be ascribed to the mechanical degradation of polypyrrole electrodes during the volume change associated with the doping-dedoping process. It may be improved by producing nanostructured polypyrrole films ${ }^{46,47}$ or composing it with carbon based materials such as carbon nanotubes, and graphene. ${ }^{48,49}$

\section{CONCLUSION}

We successfully developed a highly stretchable polymer electrolyte with high conductivity $\left(3.4 \times 10^{-3} \mathrm{~S} \mathrm{~cm}^{-1}\right)$ using PVA with a molecular weight of 124,000-186,000 $\mathrm{g} \mathrm{mol}^{-1}$ and a weight ratio to $\mathrm{H}_{3} \mathrm{PO}_{4} / \mathrm{PVA}$ of 1.5 . The electrolyte was stable and displayed only $5 \%$ plastic deformation after being stretched for 1000 cycles with 100\% strain applied. The use of this stretchable polymer electrolyte as electrolyte and separator allows fabrication of an intrinsically stretchable supercapacitor with buckled, stretchable polypyrrole electrodes. Our stretchable supercapacitor exhibited comparable performance to that used traditional flat polypyrrole electrodes. This stretchable supercapacitor retained $81 \%$ of the initial capacitance even after being stretched for 1000 cycles with $30 \%$ strain applied.

\section{AUTHOR INFORMATION}

\section{Corresponding Author}

*Tel: +61 2 42981426. Fax: +61 2 42983114. E-mail: caiyun@uow.edu.au (C.W.).

Tel: +61 2 42213127. Fax: +61 2 42213124. E-mail: gwallace@uow.edu.au (G.G.W.). 


\section{ACKNOWLEDGMENTS}

The authors thank the Australian Research Council (ARC) for financial support under the ARC Centre of Excellence for Electromaterials Science, and the ANFF Materials Node for their

provision of research facilities. Chen Zhao acknowledges the support of the CSC scholarship from the Ministry of Education of P. R. China. The authors also acknowledge the use of facilities within UOW Electron Microscopy Centre.

\section{REFERENCES}

(1) Rogers, J. A.; Someya, T.; Huang, Y. Science 2010, 327, 1603-1607.

(2) Khang, D.-Y.; Jiang, H.; Huang, Y.; Rogers, J. A. Science 2006, 311, 208-212.

(3) Yu, Z.; Niu, X.; Liu, Z.; Pei, Q. Adv. Mater. 2011, 23, 3989-3994.

(4) Yu, Z.; Zhang, Q.; Li, L.; Chen, Q.; Niu, X.; Liu, J.; Pei, Q. Adv. Mater. 2011, 23, 664-668.

(5) Lee, S.-K.; Kim, B. J.; Jang, H.; Yoon, S. C.; Lee, C.; Hong, B. H.; Rogers, J. A.; Cho, J. H.; Ahn, J.-H. Nano Lett. 2011, 11, 4642-4646.

(6) Park, K.; Lee, D. K.; Kim, B. S.; Jeon, H.; Lee, N. E.; Whang, D.; Lee, H. J.; Kim, Y. J.; Ahn, J. H. Adv. Funct. Mater. 2010, 20, 3577-3582.

(7) Shin, G.; Yoon, C. H.; Bae, M. Y.; Kim, Y. C.; Hong, S. K.; Rogers, J. A.; Ha, J. S. Small 2011, 7, 1181-1185.

(8) Ko, H. C.; Huang, Y.; Rogers, J. A.; Stoykovich, M. P.; Song, J.; Malyarchuk, V.; Choi, W. M.; Yu, C.-J.; Geddes, r. J. B.; Xiao, J.; Wang, S. Nature 2008, 454, 748-753. 
(9) Hu, X.; Krull, P.; de Graff, B.; Dowling, K.; Rogers, J. A.; Arora, W. J. Adv. Mater. 2011, 23, 2933-2936.

(10) Sekitani, T.; Nakajima, H.; Maeda, H.; Fukushima, T.; Aida, T.; Hata, K. Nat. Mater .2009, 8, 494-499.

(11) Yamada, T.; Hayamizu, Y.; Yamamoto, Y.; Yomogida, Y.; Izadi-Najafabadi, A.; Futaba, D. N.; Hata, K. Nat. Nanotechnol .2011, 6, 296-301.

(12) Xu, F.; Zhu, Y. Adv. Mater. 2012, 24, 5117-5122.

(13) Yu, C.; Masarapu, C.; Rong, J.; Wei, B.; Jiang, H. Adv. Mater. 2009, 21, 4793-4797.

(14) Li, X.; Gu, T.; Wei, B. Nano Lett. 2012, 12, 6366-6371.

(15) Hu, L.; Pasta, M.; Mantia, F. L.; Cui, L.; Jeong, S.; Deshazer, H. D.; Choi, J. W.; Han, S. M.; Cui, Y. Nano Lett. 2010, 10, 708-714.

(16) Yue, B.; Wang, C.; Ding, X.; Wallace, G. G. Electrochim. Acta 2012, 68, 18-24.

(17) Kaltenbrunner, M.; Kettlgruber, G.; Siket, C.; Schwödiauer, R.; Bauer, S. Adv. Mater. 2010, 22, 2065-2067.

(18) Gaikwad, A. M.; Zamarayeva, A. M.; Rousseau, J.; Chu, H.; Derin, I.; Steingart, D. A. Adv. Mater. 2012, 24, 5071-5076.

(19) Xu, S.; Zhang, Y.; Cho, J.; Lee, J.; Huang, X.; Jia, L.; Fan, J. A.; Su, Y.; Su, J.; Zhang, H.; Cheng, H.; Lu, B.; Yu, C.; Chuang, C.; Kim, T.-i.; Song, T.; Shigeta, K.; Kang, S.; Dagdeviren, C.; Petrov, I.; Braun, P. V.; Huang, Y.; Paik, U.; Rogers, J. A. Nat. Commun. 2013, 4, 1543. 
(20) Jost, K.; Stenger D.; Perez, C.R.; McDonough, J.K.; Lian, K.; Gogotsi, Y.; Dion, G. Energy Environ. Sci. 2013, DOI: 10.1039/ c3ee40515j.

(21) Winter, M.; Brodd, R. J. Chem. Rev. 2004, 104, 4245-4270.

(22) Meyer, W. H. Adv. Mater. 1998, 10, 439-448.

(23) Manuel Stephan, A.; Nahm, K. S. Polymer 2006, 47, 5952-5964.

(24) Manuel Stephan, A. Eur. Polym. J. 2006, 42, 21-42.

(25) Croce, F.; Appetecchi, G. B.; Persi, L. Nature 1998, 394, 456-458.

(26) Rikukawa, M.; Sanui, K. Prog. Polym. Sci .2000, 25, 1463-1502.

(27) Freitas, F. S.; de Freitas, J. N.; Ito, B. I.; De Paoli, M.-A.; Nogueira, A. F. ACS Appl. Mater. Interfaces 2009, 1, 2870-2877.

(28) Ahn, S. K.; Ban, T.; Sakthivel, P.; Lee, J. W.; Gal, Y.-S.; Lee, J.-K.; Kim, M.-R.; Jin, S.H. ACS Appl. Mater. Interfaces 2012, 4, 2096-2100.

(29) Trapa, P. E.; Won, Y.-Y.; Mui, S. C.; Olivetti, E. A.; Huang, B.; Sadoway, D. R.; Mayes, A. M.; Dallek, S. J. Electrochem. Soc. 2005, 152, A1.

(30) Saricilar, S.; Antiohos, D.; Shu, K.; Whitten, P. G.; Wagner, K.; Wang, C.; Wallace, G. G. Electrochem. Commun. 2013,32, 47-50.

(31) Yuan, L.; Chen, J.; Hu, C.; Tong, Y.; Zhou, J.; Wang, Z. L.; Lu, X.-H.; Xiao, X.; Zhai, T.; Dai, J.; Zhang, F.; Hu, B.; Wang, X.; Gong, L. ACS Nano 2012, 6, 656-661.

(32) Meng, C.; Liu, C.; Chen, L.; Hu, C.; Fan, S. Nano Lett. 2010, 10, 4025-4031. 
(33) Niu, Z.; Dong, H.; Zhu, B.; Li, J.; Hng, H. H.; Zhou, W.; Chen, X.; Xie, S. Adv.Mater. 2013, 25, 1058-1064.

(34) Wang, C.; Zheng, W.; Yue, Z.; Too, C. O.; Wallace, G. G. Adv. Mater. 2011, 23, 35803584.

(35) Stoller, M. D.; Ruoff, R. S. Energy Environ. Sci. 2010, 3, 1294-131.

(36) Fox, T. G.; Flory, P. J. J. Appl. Phys. 1950, 21, 581-591.

(37) Tsukeshiba, H.; Huang, M.; Na, Y.-H.; Kurokawa, T.; Kuwabara, R.; Tanaka, Y.; Furukawa, H.; Osada, Y.; Gong, J. P. J. Phys. Chem. B 2005, 109, 16304-16309.

(38) Wu, W.; Tian, H.; Xiang, A. J. Polym.Environ. 2012, 20, 63-69.

(39) Kufian, M. Z.; Majid, S. R.; Arof, A. K. Ionics 2007, 13, 231-234.

(40) Chen, H. P.; Fergus, J. W.; Jang, B. Z. J. Electrochem. Soc. 2000, 147, 399-406.

(41) Malathi, J.; Kumaravadivel, M.; Brahmanandhan, G. M.; Hema, M.; Baskaran, R.; Selvasekarapandian, S. J. Non-Cryst. Solids 2010, 356, 2277-2281.

(42) Gamby, J.; Taberna, P. L.; Simon, P.; Fauvarque, J. F.; Chesneau, M. J. Power Sources 2001, 101, 109-116.

(43) Di Fabio, A.; Giorgi, A.; Mastragostino, M.; Soavi, F. J. Electrochem. Soc. 2001, 148, A845.

(44) Carmo, J.P., Correia, J.H. Microelectro. J. 2009, 40, 1746-1754.

(45) Hashmi, S.A., Latham, R.J., Linford, R.G., Schlindwein, W.S. Polym. Int. 1998, 47, 28-33. 
(46) Zang, J.; Li, C. M.; Bao, S.-J.; Cui, X.; Bao, Q.; Sun, C. Q. Macromolecules 2008, 41, 7053-7057.

(47) Huang, J.; Wang, K.; Wei, Z. J. Mater. Chem. 2010, 20, 1117-1121.

(48) Yang, Y.; Wang, C.; Yue, B.; Gambhir, S.; Too, C. O.; Wallace, G. G. Adv. Energy Mater. 2012, 2, 266-272.

(49) Li, X.; Zhitomirsky, I. J. Power Sources 2013, 221, 49-56. 


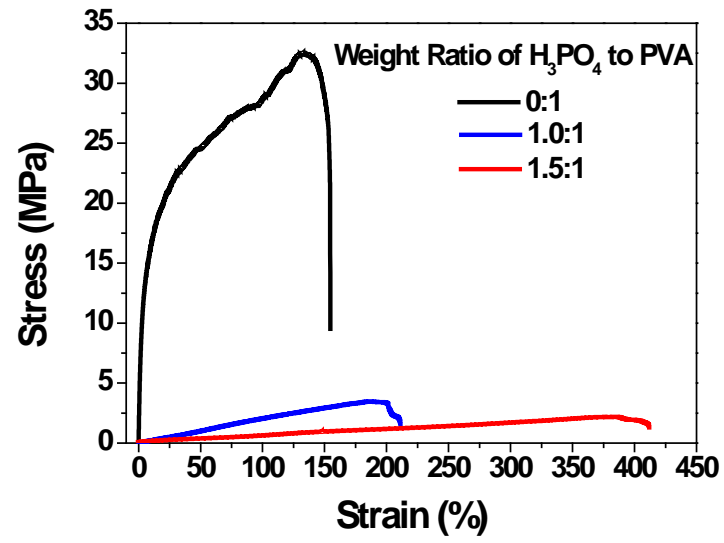

Figure 1 

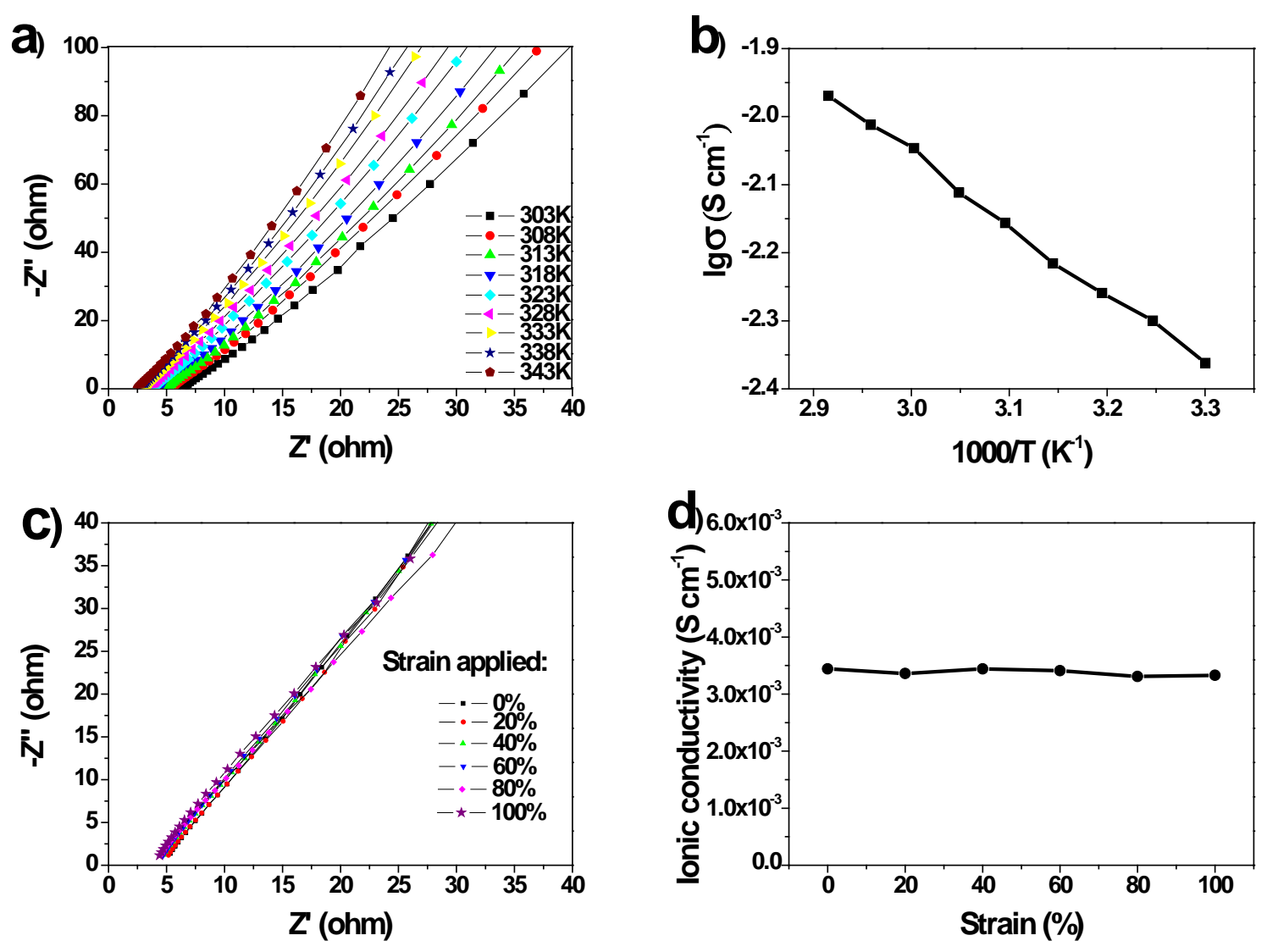

Figure 2 


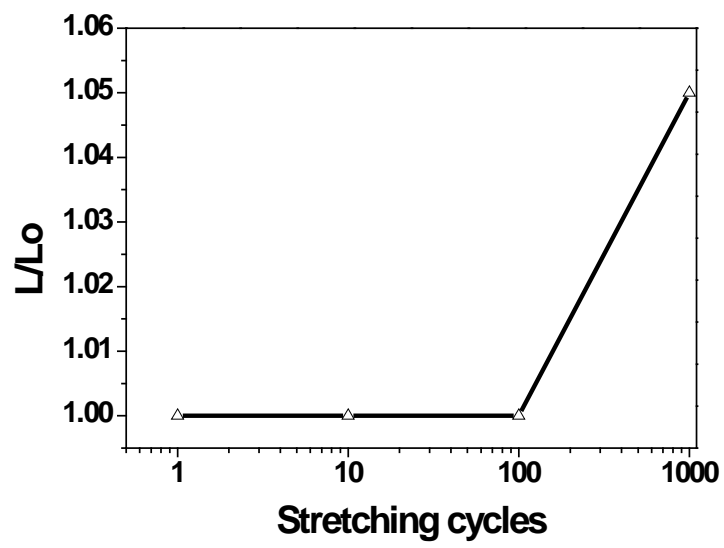

Figure 3 

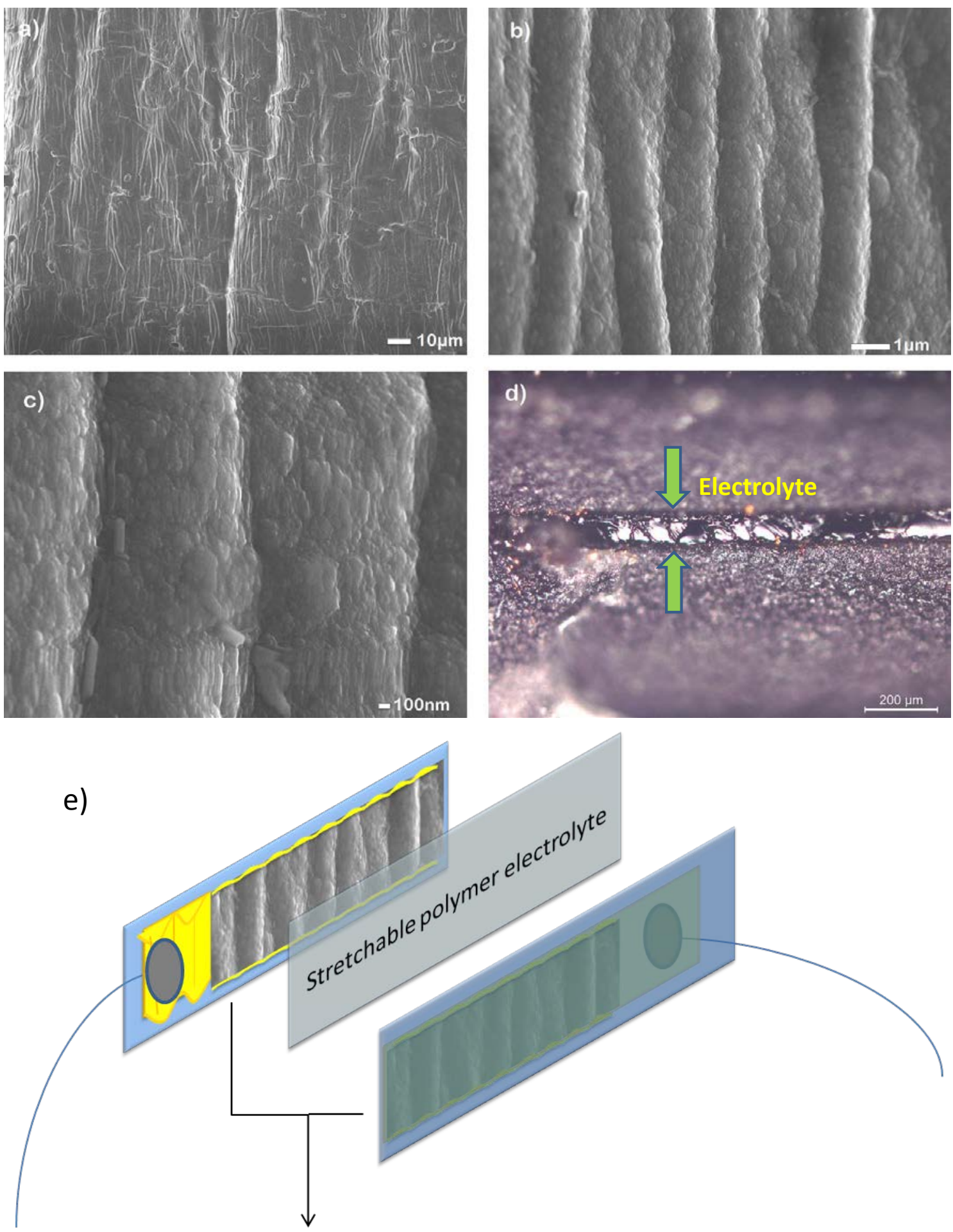

Buckled, stretchable polypyrrole electrodes

Figure 4 

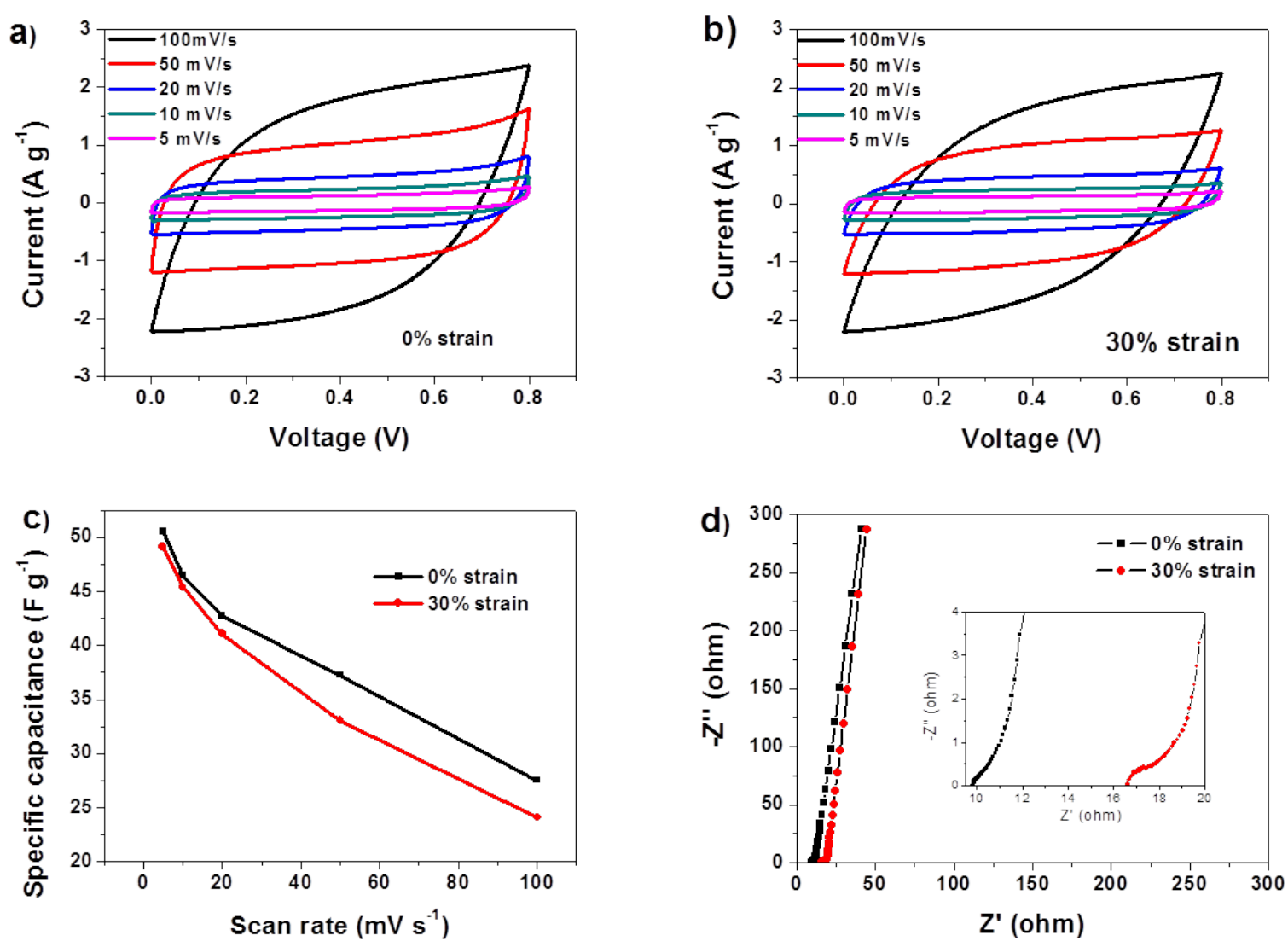

Figure 5 

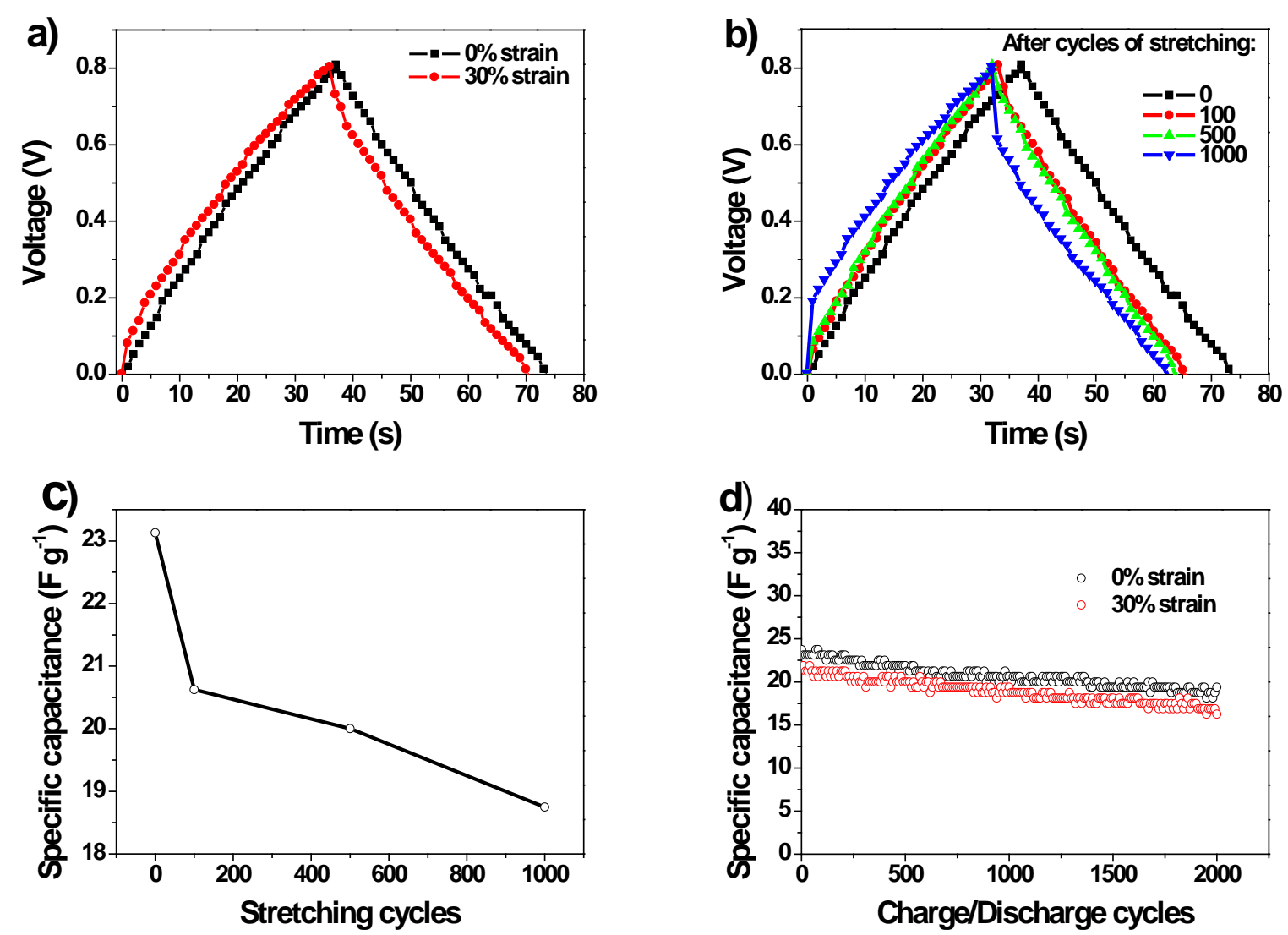

Figure 6 


\section{Captions}

Figure1: Stress-strain curves of pure PVA and $\mathrm{H}_{3} \mathrm{PO}_{4}-\mathrm{PVA}$ electrolytes.

Figure2: (a) Nyquistplots of $\mathrm{H}_{3} \mathrm{PO}_{4}$-PVA electrolyteat different temperature. (b) Temperature dependence of theconductivity of $\mathrm{H}_{3} \mathrm{PO}_{4}$-PVA electrolyte. (c) Nyquistplots of $\mathrm{H}_{3} \mathrm{PO}_{4}$-PVA electrolyte under different strain at room temperature. (d) Ionic conductivity of $\mathrm{H}_{3} \mathrm{PO}_{4}-\mathrm{PVA}$ electrolyte under different strain at room temperature.

Figure 3:Plastic deformation of the $\mathrm{H}_{3} \mathrm{PO}_{4}$-PVA electrolyte with stretching cycle number at $100 \%$ strain.

Figure4: FE-SEM images of buckled polypyrrole electrodes at low (a)and high magnification(b, c). (d) Optical image of the cross-section of the stretchablesupercapacitor. (e) Schematic configuration of the intrinsically stretchablesupercapacior.

Figure5: CV curves of the stretchable supercapacitor at different scan rateswith $0 \%$ (a) and 30\% (b) strain applied. (c) Specific capacitances of the stretchable supercapacitor with 0\% and 30\% strain as a function of scan rates. (d) Nyquist plots of the stretchable supercapacitor with $0 \%$ and $30 \%$ strain with frequency ranging from $100 \mathrm{kHz}$ to $0.01 \mathrm{~Hz}$.

Figure 6: (a) Charge-discharge curves of the stretchable supercapacitorwith $0 \%$ and $30 \%$ strain at a current density of $0.5 \mathrm{~A} \mathrm{~g}^{-1}$. (b) Charge-discharge curves of the stretchable supercapacitor before and after stretching cycles. (c) Specific capacitances of the stretchable supercapacitor as a function of stretching cycle number. (d) Specific capacitances of the stretchable supercapacitor with $0 \%$ and $30 \%$ strain as a function of charge-discharge cycles. 
Abstract graphic

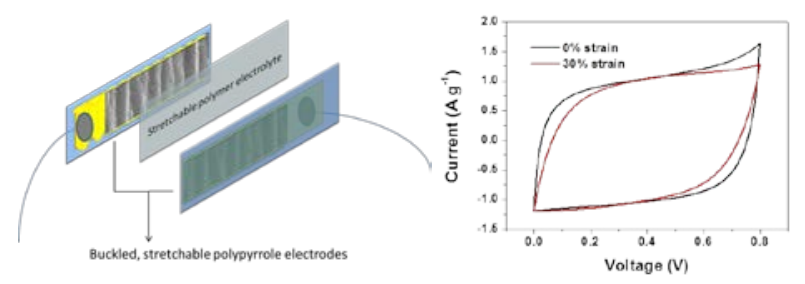

